\title{
GEOPOLÍTICA DO SÉCULO XXI: A PERSPECTIVA CHINESA DO SISTEMA INTERNACIONAL
}

Filipe Giuseppe Dal Bo Ribeiro

Resumo: O presente artigo é um estudo sobre a perspectiva geopolítica chinesa das relações internacionais. O estudo apresenta a visão dos pensadores chineses sobre 0 acirramento nas relações sino-americanas. A partir dos pensadores tradicionais do pensamento chinês aplicados a Teoria moderna das Relações Internacionais, o idealismo cultural e o realismo moral são contribuições e conceitos não muito aprofundados no ocidente que podem dar resposta para a projeção da China como liderança mundial. A pesquisa analisa a postura da China no cenário de concorrência estratégica com Estados Unidos e os possíveis impactos da pandemia na busca do sonho chinês.

Palavras-chave: Realismo Moral. Idealismo Cultural. Amizade Superficial. Autoridade Humana e Equilíbrio de Poder.

\section{ST CENTURY GEOPOLITICS: THE CHINESE PERSPECTIVE OF THE INTERNATIONAL SYSTEM}

Abstract: This article is a study on the Chinese geopolitical perspective of international relations. The study presents the view of Chinese thinkers on the tightening of Chinese American relations. From the traditional thinkers of Chinese thought applied to the Modern Theory of International Relations, cultural idealism and moral realism are contributions and concepts that are not very deep in the West that can respond to China's projection as a world leader. The research analyzes China's stance in the scenario of strategic competition with the United States and the possible impacts of the pandemic in the pursuit of the Chinese dream.

Keywords: Moral Realism. Cultural Idealism. Superficial Friendship. Human Authority and Balance of Power.

\section{GEOPOLÍTICA DEL SIGLO XXI: LA PERSPECTIVA CHINA DEL SISTEMA INTERNACIONAL}

Resumen: Este artículo es un estudio sobre la perspectiva geopolítica china de las relaciones internacionales. El estudio presenta la opinión de los pensadores chinos sobre el endurecimiento de las relaciones chino-estadounidenses. De los pensadores tradicionales del pensamiento chino aplicado a la teoría moderna de las relaciones internacionales, el idealismo cultural y el realismo moral son contribuciones y conceptos que no son muy profundos en Occidente y que pueden responder a la proyección de China como líder mundial. La investigación analiza la postura de China en el escenario de competencia estratégica con Estados Unidos y los posibles impactos de la pandemia en la búsqueda del sueño chino.

Palabras clave: Realismo moral. Idealismo cultural. Amistad superficial. Autoridad humana y Equilibrio de poder.

\footnotetext{
${ }^{1}$ Universidade de São Paulo, Fundação Escola de Sociologia e Política de São Paulo, São Paulo, Brasil, filipegiuseppe@gmail.com, https://orcid.org/0000-0003-0486-4212
} 


\section{Introdução}

As relações entre China e Estados Unidos aparecem como o grande foco de análise das relações internacionais nos últimos 30 anos, chamando a atenção de cientistas políticos, sociólogos, internacionalistas, geógrafos, historiadores, jornalistas e economistas do mundo inteiro. O impacto no sistema internacional da ascensão chinesa, da década de 1980 até os dias atuais, pressionam a hegemonia dos Estados Unidos em escala global. As relações voláteis entre Estados Unidos e China vem se transformando em uma relação de competição. Num cenário de maior tensão, as disputas militares no Mar do Sul da China, a guerra comercial, disputa na bacia do Indo-Pacífico, a disputa tecnológica, a Iniciativa do Cinturão e Rota (ICR) e a parceria estratégica China-Rússia. São questões que levaram o governo Trump à Nova Estratégia de Segurança americana que em 2017, classificou Pequim e Moscou com o status de potências rivais.

Em função do aumento da influência chinesa no sistema internacional, a perspectiva chinesa é apresentada para o público ocidental, principalmente pelos trabalhos acadêmicos do Departamento de Relações Internacionais da Universidade de Tsinghua, liderados pelo Professor Yan Xuetong, da Escola Chinesa de RI de Qin Yaqing e a Tianxia de Zhao Tingyang, inaugurando para o público ocidental a influência dos pensadores pré-Chin - antes da dinastia Chin (221 a.C - 206 a.C) no pensamento contemporâneo da política externa chinesa. As concepções de ascensão pacífica, de política de não alinhamento, de fortalecimento da nas relações exteriores, do aumento da interdependência econômica, do liberalismo no comércio exterior, do multilateralismo e do estabelecimento de uma estratégia de amizade superficial com os Estados Unidos, todos esses conceitos foram modelados teoricamente pelo pensamento chinês e podem ser identificado nos textos desses pensadores.

Os pensadores chineses das relações internacionais, embora receosos, não acreditam que o cenário de competição entre os Estados Unidos e China repitam a Guerra Fria como muitos pensadores ocidentais vêm defendendo, uma Nova Guerra Fria. O avanço da globalização, da interdependência econômica dos países, da política de não alinhamento chinesa, o desenvolvimento pacífico seriam fatores conjunturais bem distintos do sistema bipolar da Guerra Fria, em que a competição de alianças declaradas constituía uma real e eminente ameaça existencial das partes. Não havia na chamada Guerra Fria uma intensa relação econômica entre os 
dois blocos como existe entre a China e os Estados Unidos, a vitória de um dos lados necessariamente representaria a derrota total da outra parte. Os pensadores chineses começam a entrar em um consenso que a fase de parceria entre os Estados Unidos e a China está chegando ao seu fim e começam a revisar o que deve ser a postura da China em tempos de competição, mas parece muito claro que para maior parte dos pensadores chineses essa competição não levará a uma Nova Guerra Fria, pois a contribuição chinesa para as relações internacionais vai além do pensamento realista ocidental.

A última grande questão que nos cabe pensar na atual conjuntura é, como a pandemia mundial do novo coronavirus pode impactar o sistema internacional e o sonho chinês? Qual deve ser a postura da China diante de um cenário em que os Estados estão se fechando? A sobrevivência da ascensão da China como poder real perante os Estados do sistema internacional está relacionada diretamente com 0 poder de resposta e de organização da sociedade chinesa e da sua postura diante da dificuldade dos países em desenvolvimento, do quadro de caos público, crise econômica e humanitária. Mais uma vez, o Estado chinês irá recorrer aos seus filósofos antigos, para dar uma resposta para si, para seus vizinhos e para o mundo. O conceito de potência benevolente de Yan Xuetong poderá iluminar os caminhos para que a China realize seu sonho de ser reconhecida como uma autoridade humana da sociedade internacional

\section{O pensamento geopolítico chinês: idealismo cultural e realismo moral.}

Os pensadores chineses das relações internacionais perceberam uma série de lacunas na Teoria das Relações Internacionais ocidentais. Essas teorias não conseguiam explicar a ascensão do poder chinês no século XXI, especialmente a teoria do equilíbrio do poder. Como explicar uma ascensão de poder pacífico em um sistema de equilíbrio hegemônico? Para responder tal pergunta seria necessário criar uma teoria com bases na cultura e filosofia chinesa, apresentando uma perspectiva chinesa da Teoria das Relações Internacionais.

Segundo os professores chineses, uma Teoria das Relações Internacionais chinesa não deveria "apenas sinocizar teorias ocidentais como realismo, liberalismo e construtivismo, mas desenvolver teorias da cultura chinesa e universalizá-las por meio de interações com outras pessoas". (YAQING, 2006:7). A ideia de que qualquer teoria das Relações Internacionais "está sempre profundamente enraizada no lugar e posição de uma nação no sistema internacional" (FANG, 1992: 38) confronta o universalismo ocidental das Teorias das Relações internacionais e se 
aproxima muito mais do universalismo proposto pelos pensadores geopolíticos que se dividem em escolas nacionais, ou seja, a partir da percepção nacional do sistema internacional, adequando leis gerais sistêmicas aos interesses e preocupações nacionais.

A partir de 1980, três principais linhas do pensamento contribuem com o discurso da política externa chinesa, embora com algumas diferenças entre si, todas elas estão profundamente enraizadas em bases da filosofia e cultura chinesa, "houve três principais fontes sugeridas para o pensamento chinês de Rl: o marxismo, a filosofia chinesa e a confluência das tradições intelectuais ocidentais e chinesas" (ACHARYA, 2019: 470)

'Teoria relacional' de Qin Yaqing, que é o estudioso fundador da 'Escola Chinesa de RI', a Tianxia ('all under Heaven'), aplicado a RI e ordem mundial por Zhao Tingyang, e 'Realismo Moral' de Yan Xuetong, que é a figura principal da 'Escola Tsinghua'. (ACHARYA, 2019: 468).

As três interpretações destacam a necessidade da cultura chinesa em desenvolver um pensamento próprio na política das Relações Internacionais, pois as Teorias das Relações Internacionais ocidentais pensam o mundo de sua própria perspectiva, dificultando o uso delas para os problemas chineses em questões internacionais, "a China precisaria de sua própria teoria para proteger seus próprios interesses nacionais" (ZICHENG, 2005:65).

Das três teorias, é o "Realismo Moral" de Yan Xuetong que será a principal influência do pensamento chinês no mundo nas primeiras décadas do século XXI, pois tem a pretensão de construir um pensamento universal das relações internacionais, a partir de uma base na produção cultural chinesa. "Yan Xuetong, argumentando que a teoria de RI deve e pode ser universal, mesmo se derivada da cultura chinesa" (ACHARYA, 2019:470). Esse aspecto fez Yan Xuetong negar a ideia de uma Escola Chinesa das Relações Internacionais como proposto por Qin Yaqing, pois a teoria deve servir como uma perspectiva chinesa das relações internacionais, podendo ser aplicada de forma universal. Dessa ruptura estabelecida por Xuetong, de acordo com ACHARYA (2019:469) podemos dividir essas três teorias em dois grandes grupos: 0 idealismo cultural e o realismo moral. Sendo que Yaqing e Tingyang estão mais relacionados ao primeiro grupo, e Yan Xuentong e a Escola de Tsinghua ao segundo. Qin Yaqing e Zhao Tingyang podem ser colocados juntos sob o Idealismo Cultural, principalmente porque ambos compartilham um forte ethos idealista fundamentado na história, cultura e identidade chinesas. Enquanto, Yan Xuetong, prefere usar a filosofia chinesa para entender as 
possíveis dinâmicas de um sistema de anarquia interestatal, assim, abraçando uma análise realista das relações internacionais.

\section{O idealismo cultural: a grande harmonia universal e a dialética chinesa.}

Qin Yaqing é notavelmente o fundador do termo Escola Chinesa de Relações Internacionais, ele combina a teoria relacional confucionista combinando a Tianxia proposta por Zhao Tingyang. As teorias respectivas podem ser identificadas pelo termo idealismo cultural, pois adotam uma visão benigna da natureza humana e acreditam "na possibilidade de entendimento e cooperação mútuos entre os países, levando a evitar a guerra e a realizar a paz e a governança mundial" (ACHARYA, 2019:471). O idealismo cultural pode ser subdividido epistemologicamente pela teoria relacionalista de Qin Yaqing e pelo estruturalismo de Zhao Tingyang. Segundo ACHARYA (2019:471), embora o trabalho de Tingyang seja principalmente sobre o conceito de Tianxia, mais filosófico, o foco de Yaqing é a relacionalidade chinesa, zhongyong. Entretanto, Yaqing também abraça Tianxia, enquanto Tingyang acredita firmemente na relacionalidade, portanto, existe uma grande sobreposição dos dois trabalhos, o primeiro, mais filosófico, e o segundo, mais interessado na Teoria das Relações Internacionais.

A Tianxia seria um sistema baseado no mundo e não na nação, "portanto, o desafio da arte de governar é a construção do mundo, não a construção da nação. $A$ partir disso, Zhao (Tingyang) desenvolve a noção de soberania mundial" (ACHARYA, 2019:474). Segundo TINGYANG (2018:6), a Tianxia deve ser estabelecida de modo a ser um sistema mundial baseado na ontologia da coexistência por meio da racionalidade relacional, que prioriza a minimização da hostilidade mútua sobre a maximização do interesse exclusivo, em contraste com a racionalidade individual que atribui a prioridade para a maximização do interesse próprio.

Segundo ACHARYA (2019:474), a tradução de Tingyang do conceito de Tianxia, quando aplicada as Relações Internacionais, tem quatro elementoschave: não exclusão, ou a exclusão de nada e ninguém ou a inclusão de todos os povos e todas as terras; Instituição Mundial, a dinastia Zhou (IX a.C- 256 a.C) escolheu o mundo, não o estado como ponto de partida para o pensamento político; democracia a nível internacional: a democracia doméstica sem democracia internacional pode levar à hegemonia imperialista. Uma instituição é boa se, e somente se, puder ser aplicada em todos os níveis políticos, da mais básica à mais 
alta, e da dimensão local à mundial, levando assim a um sistema político universal; harmonia sobre igualdade.

\begin{abstract}
Zhao apresenta Tianxia como "uma escolha comum feita por todos os povos do mundo, ou um acordo universal nos" corações "de todas as pessoas"; e como "um sistema político para o mundo com uma instituição global para garantir a ordem universal". Ele rejeita o modelo Westfaliano e o culpa por problemas de conflito e falha do Estado. Tianxia toma o "mundo inteiro como uma unidade" e expande o conceito de política internacional "introduzindo a dimensão da política global". (ACHARYA, 2019:475)
\end{abstract}

Segundo ACHARYA (2019:475), dois pontos sobre a ordem Tianxia podem ser anotados brevemente. Primeiro, o Sistema Zhou (IX a.C - 256 a.C), período da Tianxia, refletiu uma época em que a China não tinha uma concepção do mundo além de sua área de cultura imediata, dando assim um significado empírico estreito a 'tudo sob o céu'. O segundo ponto é que a solução de Zhou para o problema da governança não foi eficaz a longo prazo. A dinastia Zhou declinou, tornando-se um sistema bastante nominal, com o rei Zhou se tornando uma figura de proa entre os governantes mais poderosos da região, e a harmonia aspirada do sistema Tianxia, período de Primavera e Outono (770 a.C. - 446 a.C), foi se degenerando na anarquia interestatal do período dos Reinos Combatentes (V a.C - 221 a.C.).

A Teoria Relacional de Yaqing apresenta dois conceitos chaves: a ideia de Datong, a grande harmonia universal baseada em Tianxia; e a relacionalidade chinesa zhongyong, em outras palavras, a dialética chinesa, baseada nos conceitos do taoísmo, o yin e yang.

É verdade que Yaqing combina o conceito de Datong com a ação dialética, entretanto a dialética clássica chinesa se difere da dialética hegeliana, segundo o pensador chinês. O argumento é que enquanto as forças opostas se chocam e geram algo diferente, o conceito de zhongyong baseado na filosofia do yin e yang, cujas partes são complementares e a harmonia não seria possível sem uma das partes, "os dois extremos da dialética chinesa são não conflitantes e inclusivos para começar" (ACHARYA, 2019:472).

Concorda com a dialética hegeliana, na medida em que ambos entendem as coisas como consistindo em polaridades e seus desenvolvimentos através da interação de tais polaridades. Mas difere da dialética hegeliana, pois a dialética de zhongyong interpreta o estado básico do relacionamento entre as duas polaridades como harmonioso, enquanto a dialética hegeliana vê o conflito como a natureza desse relacionamento. A diferença é fundamental. (YAQING apud ACHARYA, 2019:473)

Para Qin Yaqing, a Teoria Relacionalista não é melhor e nem superior a dialética ocidental, apenas ela destaca a harmonia resultante das forças universais opostas, enquanto a dialética ocidental ressalta mais a contradição e o conflito. Para 
o professor da Escola Chinesa de Relações Internacionais, as teorias ocidentais privilegiam a racionalidade sobre a emoção, quando as relações sociais são pautadas mais pelo afeto e pela solidariedade, assim como os "estados e atores não estatais frequentemente baseiam sua ação em relacionamentos. São os relacionamentos que fazem o mundo girar" (ACHARYA, 2019:472). De acordo com Professor Yaqing, a contradição é a chave para síntese no processo dialético de influência hegeliana, enquanto a "dialética de zhongyong sempre tenta encontrar o meio apropriado onde se encontra o terreno comum" (YAQING apud ACHARYA, 2019:473).

O professor chinês busca se distanciar de algum juízo de valor, e abarca conceitos possíveis de serem universalizados, entretanto, implica "que o Ocidente presta mais atenção à dimensão negativa, ou para superar e destruir, a China mais para a dimensão positiva ou para capacitar e produzir" (ACHARYA, 2019:473). Pensando por esse caminho, uma transformação do sistema internacional relacionado a ascensão da China, incide em não obedecer necessariamente a uma disputa por hegemonia ou por substituição hegemônica.

Muitos são os críticos no ocidente que acabam classificando a Teoria Relacionalista de Qin Yaqing, como uma espécie de humanização das Relações Internacionais muito próximo do que a corrente construtivista realiza, outros apontam que as teorias da Escola Chinesa de Relações Internacionais apresentam uma carga culturalista não muito diferente do que o discurso imperialista, referenciado no conceito da moral, vem produzindo historicamente. Sendo uma teoria, na visão do pensamento ocidental, que mascara as reais intenções de dominação do Estado Chinês, não muito diferente do culturalismo, próprio do imperialismo ocidental, embora essa mesma crítica, também seja dirigida ao realismo moral.

\section{O Realismo Moral: a ascensão pacífica em um sistema internacional de equilíbrio hegemônico}

A Escola de Relações Internacionais de Tsinghua, liderada pelo professor Yan Xuetong, diferente do idealismo cultural de Tingyang e Yaqing, "abraça noções realistas de anarquia e política de poder na $\mathrm{RI}$, mas vê certos tipos de moralidade e ética como uma ferramenta necessária para gerenciar a anarquia global e a ascensão da China" (ACHARYA, 2019:471). O momento histórico analisado pelo professor Xuetong, como ponto de partida é o período dos Reinos Combatentes (475 a.C - 221 a.C), momento de ascensão hegemônica do Estado de Chin, 
momento posterior a decadência de Zhou, fim da Tianxia e início da anarquia interestatal. A escolha do período dos Reinos Combatentes seria análoga ao atual sistema internacional baseado no equilíbrio hegemônico, assim escolhido pela Escola de Tsinghua, por permitir que uma experiência histórica chinesa contribua com ferramentas práticas para uma ascensão de poder sem um confronto fatal com o estado hegemônico.

Tal experiência histórica, pode ensinar para China atual os caminhos de uma ascensão pacífica. Por esse motivo, o Professor Xuetong descarta a Tianxia, pois fala de um Império Mundial governado por harmonia, benevolência e coexistência, pois essa experiência não se assemelha as condições vividas pela China no contexto atual da sociedade internacional. Segundo ACHARYA (2019:476), a questão subjacente contida nas linhas centrais do pensamento de Yan Xuetong é como um poder crescente pode diminuir a diferença de poder vis-à-vis das potências líderes existentes, ao adotar uma política de liderança pelo exemplo, que conduz à ordem internacional, assegurando ao mesmo tempo sua ascensão ao poder e à liderança globais.

Não é primazia da Escola de Relações Internacionais de Tsinghua o uso de exemplos históricos para entender o comportamento dos Estados e de sua luta pelo poder em determinadas conjunturas históricas para estabelecer comparações com a conjuntura vivida. $O$ realismo político sempre partiu de exemplos históricos para entender o comportamento dos Estados, entretanto esses exemplos explicam o sistema internacional eurocentrado. A primazia dos pensadores chineses de Tsinghua foi trazer para o conjunto da teoria das relações internacionais a experiência histórica de uma potência ascendente que não se configura como um Estado de raízes históricas eurocentradas em um sistema de anarquia interestatal. E a grande questão encabeçada por Yan Xuetong, por que a história e a experiência do povo chinês não podem ser válidas para explicar as relações dos Estados em um sistema global, em que o poder é muito mais difundido no que no período das ordens internacionais europeias?

A abordagem de Yan está mais próxima do realismo clássico, semelhante a Morgenthau, que ele acredita que abre espaço para considerações morais na política externa, em vez do neorrealismo de Mearsheimer, que exclui qualquer papel da moralidade. (ACHARYA, 2019:476)

As duas noções do moralismo do realismo chinês são destacadas pelo Professor Xuetong: "trata-se de 'moralidade governamental'; e (ii) é uma noção instrumental de moralidade. Como ele diz, 'o realismo moral adota uma abordagem 
instrumental" (ACHARYA, 2019:477). O Professor de Tsinghua não acredita ser possível uma abordagem das relações internacionais sem considerar o aspecto moral das relações, assim, o realismo moral é uma "abordagem para entender o comportamento de uma grande potência quando a moralidade é um fator que contribui para as preferências estratégicas de sua liderança" (XUETONG, 2019:7). Entretanto a moralidade governamental difere da moralidade pública, "uma vez que a primeira também pode incluir normas morais adotadas por cidadãos que diferem daquelas apresentadas por seu governo" (ACHARYA, 2019: 477). Para o professor de Tsinghua, a moralidade governamental é a responsabilidade do governo em relação ao interesse de quem governa, dessa forma uma moralidade universal e não nacional.

Governança global significa distribuição de responsabilidade internacional para reduzir ameaças comuns a todos os países. Se os estados líderes estiverem dispostos a assumir mais responsabilidade na governança global, os estados menores terão mais confiança para alcançar a meta. Caso contrário, eles perderão o interesse, porque a governança global está além de sua capacidade. (XUETONG, 2019:7)

Diferente do "idealismo cultural" que rejeita a Ordem de Vestfália, Yan Xuetong não acredita que o mundo transcendeu a anarquia interestatal. "A política mundial ainda é caracterizada pela luta entre estados por poder, prestígio e riqueza em meio à anarquia global" (XUETONG, 2019:7). O caminho moral diante de um cenário em que a potência ascendente não quer necessariamente afrontar o poder hegemônico, é o que o Professor Yan conceitua como wang dao, o caminho real. Segundo ACHARYA (2019:478), o caminho real enfatiza a retidão e benevolência sobre as noções ocidentais de igualdade e democracia. Entretanto, essas noções não competem com as noções ocidentais, mas podem complementar as normas liberais ocidentais de justiça e equidade, "podem, de qualquer maneira, transcender os valores hegemônicos dos Estados Unidos" (XUETONG, 2013:17). A intenção do teórico chinês é enriquecer os valores liberalistas com os pensamentos tradicionais chineses, uma espécie de visão chinesa do liberalismo.

Os teóricos chineses perceberam que o tamanho do mundo diminuiu muito quando comparado com a Era Colombiana, como já dissera Mackinder em seu clássico artigo "Pivô Geográfico da História" (1904). Essa noção de mudança da escala global das Relações Internacionais, fora notado pelo pensamento geopolítico no final do século XIX. Exercitar a escala geográfica e relacioná-la em diferentes conjunturas históricas para explicar fenômenos de longo prazo não é uma primazia dos pensadores de Relações Internacionais chineses. Mas a contribuição de novos 
conceitos desenvolvidos da experiência social, histórica e cultural da China, aplicados a partir da perspectiva realista, confirmam a real possibilidade de que cada povo possa dar sua contribuição para construção de uma Teoria das Relações Internacionais mais ampla.

\section{O caminho real (wang) e o hegemon (ba): uma nova bipolaridade.}

Em 2001, quando foi declarada a Doutrina Bush, os pensadores da Escola de Relações Internacionais de Tsinghua, liderados por Yan Xuetong, começaram a estudar os filósofos pré-Chin. O primeiro trabalho do Professor chinês sobre o assunto é de 2005. A doutrina de segurança americana declarou que os Estados Unidos não tinham mais um inimigo formal declarado e que teriam força para dissuadir qualquer poder que viesse a desafiar a hegemonia americana, esse período é frequentemente intitulado de Pax Americana. Tal doutrina também buscaria abertura de mercados no mundo inteiro deixando uma aresta aberta para economia chinesa que acabara de entrar na Organização Mundial de Comércio (OMC). As duas primeiras décadas do século XXI marcaram a ascensão econômica da China e uma relativa diminuição do poder econômico americano, principalmente, depois da Crise de 2008, é, exatamente, quando os Estados Unidos começam a elevar o tom nas relações com a China.

Devido a uma combinação de críticas generalizadas à política externa unilateral de George W. Bush e à ascensão de novas economias (isto é, os BRICs: Brasil, Rússia, Índia e China), a primeira década do século XXI produziu uma crítica à dominação americana da política internacional e domínio ocidental da teoria das relações internacionais. (CUNNINGHAMCROSS \& CALLAHAN, 2011:358)

Os estudos sobre os pensadores pré-Chin começaram a ser realizados na Universidade de Tsinghua pelo Professor Yan Xuetong e seu colaborador Xu Jin em 2005. A primeira publicação do projeto foi realizada em 2008, "Pre-Qin Chinese Thought on Foreign Relations" é um trabalho que selecionou, organizou e traduziu para o chinês moderno alguns textos originais dos pensadores pré-Chin, com notas e sugestões orientando estudo sobre o tema. Seu objetivo declarado é "permitir que os leitores obtenham inspiração de pensadores pré-Chin e assim, aprofundem sua compreensão da política internacional contemporânea". (Xuetong \& Jin, apud CUNNINGHAM-CROSS \& CALLAHAN, 2011:350). Em 2009, Yan e Xu publicam "Wangba tianxia sixiang ji qidi", com uma abordagem mais analítica dos textos chineses antigos. Apresenta, segundo CUNNINGHAM-CROSS \& CALLAHAN (2011:351), uma análise contemporânea aplicada as Relações Internacionais de 
pensadores como Guanzi, Laozi, Confúcio, Mencius, Mozi, Xunzi e Hanfeizi -, além de muitos outros textos importantes do período, incluindo: "A Crônica de Zuo", "Estratégias dos Estados Combatentes", "Primavera do mestre Lu", "o Livro dos Ritos", entre outros.

$O$ projeto central da escola de Relações Internacionais de Tsinghua não valeria muito se o público mundial não pudesse ter acesso. A fase de internacionalização da contribuição do pensamento chinês para a Teoria das Relações Internacionais foi concretizado na publicação em 2011, do livro "Ancient Chinese Thought, Modern Chinese Power", "é significativo porque leva o projeto pré-Chin de Yan a um novo público, apresentando esses trabalhos selecionados em inglês pela primeira vez" (CUNNINGHAM-CROSS \& CALLAHAN, 2011:351). As últimas duas publicações feitas para apreciação do público de língua inglesa em 2019 foram "Leadership and the Rise of Great Powers" e "Inertia of History: China and the World By 2023".

Segundo CUNNINGHAM-CROSS \& CALLAHAN (2011:350), Yan Xuetong acredita que os textos originários do período anterior à unificação da China durante a dinastia Chin (221 a.C) são particularmente úteis para os estudiosos hoje em dia, porque as relações interestaduais durante aquela época, compartilham muitas semelhanças com a política internacional contemporânea. Ademais, esse período é frequentemente visto como o ápice da filosofia chinesa.

Ao comparar o contexto político da China pré-Chin com atual ordem de anarquia interestatal, Xuetong estrutura sua teoria de ascensão benevolente, pois como atingir o sonho chinês de ser a maior potência do mundo sem desafiar a hegemonia americana? Para responder essa pergunta central, dois conceitos da filosofia pré-Chin são destacados na aplicação de uma política externa chinesa na conjuntura hegemônica atual: wang que significa o caminho real, ou caminho do rei, mas que foi traduzido na versão em inglês como autoridade real, como destacam CUNNINGHAM-CROSS \& CALLAHAN (2011:349); ba, significa o oposto ao wang, é a autoridade hegemônica.

O 'verdadeiro reinado', ou 'autoridade humana', é, portanto, visto como uma forma benéfica de governança e contrastada com o valor negativo da 'hegemonia', que Yan associa amplamente aos EUA e às experiências de unilateralismo americano no período pós-Guerra Fria. (CUNNINGHAMCROSS \& CALLAHAN, 2011:355)

$O$ conceito de autoridade humana ou caminho real, segundo o teórico chinês não pode ser confundido com o conceito de soft power, pois esse não difere, nem hierarquiza os elementos culturais dos elementos políticos. "Para os 
pensadores pré-Chin, são os elementos políticos que são decisivos. A fonte de todo poder político é o líder de um estado" (CUNNINGHAM-CROSS \& CALLAHAN, 2011:356). O Professor Xuetong afirma, para Confúcio, toda política é política do rei e Xunzi argumenta que "o que torna um país seguro ou em perigo, bom ou ruim, é determinado exclusivamente por seu governante e não por outros" (XUETONG, 2009: 53).

Yan argumenta que a teoria contemporânea da estabilidade hegemônica ignorou a relação entre a natureza do poder hegemônico e a estabilidade do sistema interestadual. Ele usa exemplos de Xunzi para mostrar como o wang pode criar um ambiente internacional estável, enquanto um estado dependente exclusivamente de forças militares alienará os outros e criará inimigos com efeitos potencialmente desestabilizadores para o sistema internacional. (CUNNINGHAM-CROSS \& CALLAHAN, 2011:357)

Em seu recente livro publicado em 2019 pela The Princeton-China Series, "Leadership and the Rise of Great Powers", Yan Xuetong alerta as possibilidades da ordem internacional se transformar em uma ordem bipolar, como apresenta LARSON (2020: 164):

Mesmo que a China supere os EUA no poder geral, ela não poderá exercer liderança internacional a menos que possa atrair seguidores, o que exige articular e defender uma ideologia que agrada a outras culturas. A China tem a oportunidade de preencher o vazio deixado pelo declínio do apoio ao liberalismo e perda de prestígio e influência dos EUA devido à retirada do governo Trump de acordos e tratados internacionais. Para fazer isso, a China deve seguir consistentemente os valores morais tanto na política doméstica quanto nas relações internacionais, um requisito para a liderança moral. Sem uma política consistente e uma ideologia de substituição, a ascensão da China poderia levar a um sistema bipolar sem ideologia dominante. (LARSON, 2020: 164)

O alerta do Professor da escola de Relações Internacionais de Tsinghua, a partir de uma perspectiva chinesa de equilíbrio de poder, é dirigido principalmente as lideranças chinesas. Para Xuetong, cabe a China ser uma liderança capaz de atrair seguidores na sociedade internacional, para tal ela deve ser um exemplo de liderança moral, ocupando um vácuo ideológico deixado pelo declínio moral do prestígio dos Estados Unidos nas Relações Internacionais. Assim, uma política muito agressiva por parte da China, em relação aos seus vizinhos, por exemplo, abre um espaço para aproximação dos interesses dos Estados Unidos na região, podendo levar a conjuntura internacional para uma bipolaridade que não interessa para o projeto chinês de ascensão de poder mundial. 


\section{A relação sino-americana: uma Nova Guerra Fria é inevitável?}

Nos últimos anos, muitos artigos publicados nas principais revistas de Relações Internacionais do mundo vêm chamando atenção para uma mudança nas relações entre Estados Unidos e China, apontando para inevitabilidade de uma Nova Guerra Fria. Embora o Professor Yan Xuetong não descarte em sua análise um cenário de bipolaridade, mais uma vez, ao apresentar a perspectiva chinesa da Teoria das Relações Internacionais, um quadro de novas possibilidades aparece com soluções para os obstáculos da ascensão de poder contemporânea da República Popular da China.

A partir de 2017, quando os Estados Unidos publicou a sua nova Doutrina de Segurança, elevando a Rússia e a China como potências rivais, o discurso de Yan Xuetong, que é cético em relação a uma Nova Guerra Fria, começa a vislumbrar um cenário de competição que era previsto para 2030. Um cenário de competição ainda está muito longe de uma Nova Guerra Fria, pois as relações internacionais são mais multilaterais do que eram, além das relações entre os Estados Unidos e China serem mais fluidas e interdependentes se comparado com a relação dos Estados Unidos com a União Soviética no período da Guerra Fria.

Entretanto, como alerta Xuetong, existem alguns perigos no cenário atual que podem acelerar o recrudescimento das relações sino-americanas: o aumento do ultraconservadorismo mundial, impulsionado pela guerra cibernética; a campanha ideológica contra a China, vem se intensificando no cenário da pandemia mundial, com a campanha encabeçada por Mike Pompeo, secretário de estado dos Estados Unidos, acusando a China pela pandemia e usando o termo "vírus chinês"; o aumento do protecionismo e a diminuição do comércio mundial; a disputa com as potências emergentes da Ásia e com Japão; as ameaças chinesas aos países do Mar do Sul da China. Além da questão de Formosa, que vem se aproximando militarmente dos Estados Unidos, passando a ser uma ameaça constante para política de segurança chinesa. Todos esses elementos são fatores externos que podem criar tensões indesejadas para o projeto do sonho chinês.

\section{Evolução das relações sino-americanas da Segunda Guerra Mundial aos dias atuais: de inimigos reais à competidores globais}

Pelo menos desde 2012, Yan Xuetong e seus colaboradores estão antagonizando com pensadores ocidentais sobre o teor das relações sino- 
americanas. Em seu artigo feito em colaboração com Qi Haixya , intitulado "Football Game Rather Than Boxing Match: China-US Intensifying Rivalry Does not Amount to Cold War", publicado em 2012, na The Chinese Journal of International Politics, revista de relações internacionais de Oxford, diferencia a análise feita pelos pensadores do ocidente que estão construindo um cenário futuro de Guerra Fria dividindo em um espectro entre mais pessimistas e mais otimistas - da perspectiva proposta pela Escola de Tsinghua, que apresenta novas possibilidades mais realistas e menos catastrofistas.

O conflito entre a China e os Estados Unidos nas Conversas Climáticas de Copenhague de 2009, deu origem à visão dominante nos círculos acadêmicos dos EUA, de que os laços sino-americanos estão piorando. Paul Pedrozo e Seth Cropsy argumentaram que a concorrência entre a China e os Estados Unidos era um resultado necessário da modernização naval da China. Robert Kaplan, enquanto isso, sustentava que as crescentes capacidades militares e poder econômico da China tornavam inevitáveis as tensões nas relações sino-americanas. Thomas Christensen sustenta que as relações entre os dois países ficarão estressadas à medida que a China mudar para uma política de linha dura no que diz respeito à sua soberania e reivindicações territoriais. Enquanto, em 2010, os acadêmicos dos EUA culparam a China pela deterioração das relações sino-americanas, os estudiosos chineses consideram 0 agravamento dos laços em 2011, como resultado obviamente do fortalecimento do governo Obama e de sua estratégia de pivô na região Ásia-Pacífico. (XUETONG \& HAIXYA, 2012: 106)

Entre os que compõem os pensadores mais otimistas, segundo Xuetong, estão os estudiosos chineses entre outros. Para esses pensadores, a Nova Guerra Fria, não irá acontecer pois as partes não estão dispostas a seguir por esse caminho, ou seja, essa via só irá ocorrer por vontade de ambos, assim não existe um catastrofismo inevitável. Usando um ditado popular, para explicar a perspectiva dos pensadores chineses, "quando um não quer, dois não brigam”. Alguns desses pensamentos são destacados na análise de XUETONG \& HAIXYA (2012:106-7):

Os mais otimistas sobre o futuro das relações sino-americanas são principalmente estudiosos chineses, que geralmente acreditam que é possível que a China e os Estados Unidos evitem uma nova Guerra Fria. Wu Jianmin argumenta que a China, por uma questão de política nacional, não desempenhará o papel de hegemônico, mas seguirá a tendência histórica de paz, desenvolvimento e cooperação e rejeitará absolutamente a guerra, a concorrência e o conflito. Portanto, sob nenhuma circunstância a China entrará em uma nova Guerra Fria com os Estados Unidos. Wang Jisi há muito tempo defende que, embora a China e os Estados Unidos não se tornem aliados, nem uma crise em seus vínculos surgirá de uma extensão equivalente à Guerra Fria. Wang argumenta que as contradições estruturais que surgiram entre a China e os Estados Unidos em 2010, são atribuíveis ao estreitamento da lacuna em suas respectivas capacidades comparativas, que, por outro lado, os afastaram ainda mais em termos de entendimento mútuo. Questões importantes como Taiwan, Península Coreana e a taxa de câmbio tiveram um impacto negativo 
crescente nos laços sino-americanos e criaram níveis mais altos de suspeita estratégica, em vez de confiança estratégica mútua. Isso implica que, desde que os Estados Unidos e a China fortaleçam a confiança estratégica, eles podem impedir que seu relacionamento bilateral entre no cenário da Guerra Fria. (XUETONG \& HAIXYA 2012:106-7)

A proposta que Yan e seus colaboradores apresentam foi desenvolvida a partir da análise das relações sino-americanas da Segunda Guerra Mundial até 2012 - atualizada em 2019, na sua publicação pela The Princeton-China Series. Princeton University Press, já citada. A partir de um estudo pautado no número de reuniões de Estado, Xuetong \& Haixya (2012) chegam em um coeficiente, classificando as relações sino-americanas em quatro níveis: inimigos reais (1950-70), inimigos superficiais (1971-1977), amigos reais (1978-88), amigos superficiais (19892011).

O valor durante o período inimigo real (1950-1970) para as relações sinoamericanas foi o mais baixo. Nenhuma tendência de melhoria foi observada durante esse período. Durante o período inimigo superficial (1971-1977), embora o valor para as relações sino-americanas tenha sido baixo, a mudança tendeu continuamente em direção à melhoria, e o ritmo da melhoria foi mais rápido. Durante o período de amigos reais (1978-1988) e amigos superficiais (1989-2011), a extensão da mudança nas relações sinoamericanas foi principalmente entre $(-2,3)$, tendendo a um aumento gradual. $\mathrm{O}$ ritmo de melhora durante o período amizade real, no entanto, ficou apenas atrás do período inimigo superficial e muito superior ao do período amizade superficial. (XUETONG \& HAIXYA, 2012:117)

A amizade superficial, na definição do Professor de Tsinghua, é uma relação volátil, tem momentos de pico e de vales profundos, ficando atrás do período de inimizade superficial e amizade real. "O estado a que a amizade superficial se refere é aquele em que nenhuma das duas partes se considera uma parceira estratégica, mas em que ambas reivindicam uma parceria estratégica" (XUETONG \& HAIXYA, 2012: 109). As partes só se preocupam em obter vantagem, mesmo que seja à custa da outra parte. Quando uma das partes não consegue alcançar o seu objetivo, "fica decepcionada e expressa descontentamento, culpa a outra parte ou retaliação por não cooperar, causando uma deterioração nas relações" (XUETONG \& HAIXYA, 2012: 109). As razões que sustentam a amizade superficial das relações entre Estados Unidos e China são: "globalização econômica, preocupação de longo prazo dos Estados Unidos com a guerra no Oriente Médio e estratégia da China para um desenvolvimento pacífico" (XUETONG \& HAIXIAY 2012:119).

Num cenário de competição, de acordo com Xuetong, é pouco provável que a relação sino-americana mude o status de amizade superficial. O pior cenário para China seria a volta da relação de inimigos reais, então desejosa de não confrontar 
diretamente os Estados Unidos, a amizade superficial tende a permanecer, mesmo em um cenário de competição entre ambos. Ao rebater algumas críticas sobre o conceito de amizade superficial, Xuetong \& Haixiay, afirmam:

\begin{abstract}
Alastair lain Johnston argumenta que a teoria clássica do dilema de segurança pode ser usada para explicar as relações EUA-China, e que não há necessidade de uma teoria da amizade superficial. $O$ que ele não reconhece é que a teoria do dilema de segurança pode explicar por que as relações entre a China e os Estados Unidos se deterioraram, mas não por que elas podem melhorar posteriormente, enquanto o conceito de amizade superficial explica os dois lados dessa moeda em particular, assim, respondendo efetivamente, a volatilidade das relações sino-americanas. (XUETONG \& HAIXIAY, 2012:108)
\end{abstract}

Para o Professor de Tsinghua, o cenário de parceria estratégica começa a mudar nos anos 1990, então começa um período em que a relação volátil de amizade superficial, com altos e baixos, se estabelece na relação sino-americana. Entretanto, mesmo em um cenário de competição que começa a se deflagrar em 2012, com a nova orientação política do governo Obama - intitulada "Sustentando a liderança global dos EUA: o século XXI, a Defesa do Século". O documento afirma "que a ascensão da China pode ter impacto na economia e segurança dos EUA, e que países como China e Irã continuam a buscar meios assimétricos de combater as capacidades de projeção de energia dos EUA" (XUETONG \& HAIXIAY, 2012:105) é pouco provável que esse cenário de competição leve as relações sino-americanas para o status de inimigos reais e, tão pouco, inimigos superficiais, não chegando a Guerra Fria. "A concorrência entre a China e os Estados Unidos aumentará, consequentemente, mas isso não atende aos critérios para uma Guerra Fria”, (XUETONG \& HAIXIAY, 2012: 108), assim Xuetong caracteriza a essa relação "como amigos superficiais e argumentamos que, como tal, eles têm um relacionamento altamente volátil, aparente nas mudanças entre períodos bons e ruins" (XUETONG \& HAIXIAY, 2012:108).

\title{
Estados Unidos elevam o tom: a política do Pivô Asiático e a Nova Doutrina de Segurança
}

Algumas condições da Pax Americana começaram a se transformar depois da intitulada Crise Imobiliária de 2008, que afetou sensivelmente a confiança nos investimentos financeiros mundiais e no padrão dólar. Essa conjuntura de crise econômica e baixo crescimento econômico, alterou a rota da política externa americana com relação a China. "A maioria dos observadores chineses afirma que a 
crise financeira global de 2008, constitui um divisor de águas na história das relações EUA-China" (ZHAO, 2019:374). Em 2010, a China ultrapassou o Japão, se tornando a segunda maior economia do mundo. Em 2011, a produção industrial chinesa superou a dos Estados Unidos pela primeira vez em mais de 100 anos.

O aumento da dependência de setores básicos da economia dos Estados Unidos em relação ao setor industrial chinês afeta a logística e, portanto, a grande estratégia americana. Emergiu um medo em Washington em ver suas decisões vitais para manter sua supremacia no controle político da China, dessa forma, no controle político do Partido Comunista Chinês (PCC). A leitura que podemos fazer da conjuntura nos últimos 10 anos é que os Estados Unidos estão elevando o tom das discussões com a China. Entre 2010-2012, quando o governo Obama adotou a política do Pivô Asiático para reequilibrar o poder na Bacia do Pacífico e Sudeste Asiático, tal ação foi analisada pelos observadores chineses como mais um movimento em direção ao cenário de concorrência estratégica.

A segunda onda começou em 2010-2011, quando o governo Obama promoveu a estratégia Pivot / Rebalance to Asia. Surgiu mais tensão entre Pequim e Washington sobre assuntos econômicos e de segurança regionais, em particular os decorrentes da disputa EUA-China sobre o Mar da China Meridional. Além do que, a superação do Japão pela China como segunda maior economia do mundo em 2010, alimentou as preocupações chinesas sobre um relacionamento mais desafiador com os Estados Unidos. (ZHAO, 2019: 372-3)

Um terceiro movimento da política externa americana em dezembro de 2017, concretiza o cenário de concorrência estratégica nas relações sino-americanas, a Nova Estratégia de Segurança, "o governo Trump apresentou seu relatório da Estratégia de Segurança Nacional que propunha que os Estados Unidos entrassem em uma nova era de grandes competições de poder" (ZHAO, 2019: 371). Tal relatório aponta a China "como poder revisionista e concorrente estratégico que deseja moldar um mundo antitético aos valores e interesses dos EUA" (ZHAO, 2019:371). Em 2018, o Departamento de Segurança dos Estados Unidos publicou o Resumo da Estratégia Nacional de Defesa, que enfatiza que o "desafio central do Pentágono era como enfrentar o ressurgimento da competição estratégica de longo prazo com a China e outros estados rivais" (ZHAO,2019:372). Os pensadores chineses estão trabalhando esse cenário de competição nas relações sinoamericanas há mais de uma década. Em muitos artigos, a questão se essa nova bipolaridade irá levar há uma Nova Guerra Fria, só se apresentaria válida, se considerarmos um cenário totalmente diferente do que foi a segunda metade do século $X X$. 
Novas tensões surgiram sobre a questão de Taiwan e há o risco de aumentar o atrito EUA-China em relação à Ásia marítima, especialmente no mar do sul da China. Os Estados Unidos continuam avançando sua 'Estratégia Indo-Pacífico Livre e Aberta', cujo principal objetivo é contrabalançar a Iniciativa do Cinturão e Rota que a China vem promovendo nos últimos anos. (ZHAO, 2019:372)

Diante desse quadro de recrudescimento as opiniões dos pensadores chineses começam a divergir em relação ao futuro das relações sino-americanas. Entretanto, um cenário em que a China se proponha a substituir a hegemonia americana, num verdadeiro desafio para um ringue de boxe, no famoso número 1 versus número 2, é sempre descartado pelos estrategistas chineses. De acordo com XUETONG \& HAIXIAY (2012), o melhor desafio para China seria uma partida de futebol e não uma rinha de boxe. $O$ futebol apresenta momentos de intensidade e calmarias, existe uma falsa cordialidade como é a amizade entre Estados Unidos e China. É de bom tom que a China aceite os desafios de concorrer com os Estados Unidos, pois o sonho chinês é se tornar a liderança mundial. Para tal, a China deve jogar o seu jogo e não cair nas armadilhas e provocações da potência hegemônica, conhecida como armadilha de Tucídides, isto é, quando a potência emergente desafia a potência hegemônica.

Embora, a postura da China tenha mudado em relação aos assuntos regionais, o que a maioria dos pensadores de política internacionais chineses acreditam não ser o caminho correto, a tradição das autoridades chinesas desde a Revolução tem sido a do discurso contra hegemônico. Como lembra PU (2017:132), ao citar um trecho do primeiro discurso de Deng Xiaoping nas Nações Unidas.

Antes de tudo, as autoridades chinesas têm uma longa tradição de oposição
ao status de superpotência. Em seu primeiro discurso nas Nações Unidas
em 1974, Deng Xiaoping disse: 'A China não é uma superpotência, nem
jamais procurará ser uma. Se um dia a China mudar de cor e se transformar
em uma superpotência ... as pessoas do mundo devem expô-la, opor-se a
ela e trabalhar em conjunto com o povo chinês para derrubá-la. Deng fez
esse discurso na década de 1970 , quando a China era ideologicamente
radical, economicamente fraca e diplomaticamente isolada. Na atual era de
"abertura e reforma", a China se tornou a segunda maior economia do
mundo, com uma presença global em expansão. No entanto, as autoridades
chinesas ainda evitam descrever a China como uma superpotência em
potencial. Eles associam o status de superpotência à hegemonia, que tem
uma conotação negativa no contexto chinês. (PU, 2017:132)

O Professor Yan Xuetong, acredita que para a China conseguir adeptos no sistema internacional, ela deve exercer a liderança benevolente, usando o engajamento político como a principal arma para enfrentar o hegemon e se tornar a autoridade humana, assim, concretizando o sonho chinês de ser a liderança mundial a partir de exemplos de governança humana. 


\section{Pandemia: exercer a liderança benevolente para alcançar o status de autoridade humana e de liderança global}

A atual conjuntura de pandemia mundial vem acentuando ainda mais o fosso das relações sino-americanas. Todas as ações políticas das grandes potências estão sendo analisadas e julgadas por todas as pessoas do mundo, mas, principalmente tal julgamento ocorre no âmbito da política internacional e das relações internacionais. Não é nenhum espanto que o atual governo do Brasil, já é classificado como o pior do mundo em governança humana. Não é muito diferente do caso dos Estados Unidos e do governo Trump.

Os Estados Unidos estão usando todas as armas para moldar a opinião pública contra a China, acusando as autoridades chinesas de serem responsáveis pela pandemia mundial. Os Estados Unidos deram um péssimo exemplo de exercício de liderança na conjuntura de pandemia mundial, demonstrando mais uma vez a fraqueza de um modelo de gestão privada dos assuntos públicos, desviando respiradores comprados por outros países, dificultando o repasse de ajuda do governo federal para estados governados pelos democratas, só para ficar em alguns exemplos.

A China por sua vez, usando os conceitos de governança humana se apresenta como um país que vem apoiando os países com maiores dificuldades como foi no caso da Itália, demonstrando solidariedade e empatia em um momento de dificuldade global. Sobre as provocações dos Estados Unidos em relação as suas campanhas difamatórias, a China exige explicações e pede que as provas sejam apresentadas. Outro aspecto importante, foi a organização social diante da pandemia. O presidente Xi Jinping anunciou uma guerra patriótica contra o vírus, voltando a força do Estado para o controle e combate ao novo coronavírus, apresentando para o mundo um exemplo de organização interna impressionante. A China quer ocupar um vácuo deixado pela perda de prestígio dos EUA nas relações internacionais, se apresentando como uma alternativa a política estadunidense, ao demonstrar que ainda é necessário um Estado engajado nos interesses públicos da sociedade. A pandemia mundial do novo coronavirus será, na conjuntura atual, o momento decisivo para que a China apresente o seu projeto de liderança mundial. 


\section{Os desafios da China para o reconhecimento da autoridade humana}

É um consenso entre os pensadores chineses que uma bipolaridade de balanceamento rígido como foi a Guerra Fria, seria o pior cenário para o projeto da China de se tornar a liderança mundial, usando o caminho real. Uma bipolaridade de balanceamento rígido tradicional ocorre, por meio da formação "formal de alianças e acumulação militar é significativa, mas parece capaz de capturar apenas um, embora seja a forma mais significativa de equilíbrio do comportamento do poder." (HAN \& PAUL, 2020:5). A Guerra Fria se estabeleceu a partir da negação da hegemonia americana por parte da União Soviética que respondeu com um balanceamento rígido com contra alianças, corrida armamentista, mas acabou isolada do sistema internacional, e impossibilitada de atrair seguidores para substituir a Ordem Mundial vigente.

Em recente artigo publicado em fevereiro do corrente ano, HAN \& PAUL (2020:4) classificou três formas de equilibrar ameaças, balanceamento rígido, balanceamento rígido limitado e balanceamento suave. A China por adotar uma política de não alianças formais de defesa, costumou praticar o balanceamento suave nas primeiras décadas do século XXI, isto é, um equilíbrio tácito sem alianças formais. Os estados geralmente desenvolvem ententes ou entendimentos de segurança limitados, como parcerias estratégicas ou coalizões diplomáticas para equilibrar um estado poderoso. A Iniciativa do Cinturão e Rota (ICR) é uma política externa de balanceamento suave, por exemplo. Dificilmente os países que integram o ICR entrariam numa aliança de balanceamento rígido contra China, é uma maneira da política externa chinesa neutralizar a ameaça da política hegemônica americana para Bacia do Indo-Pacífico.

Desde ascensão do Presidente Xi Jinping, a China vem deixando de lado a estratégia de manter um perfil discreto e começa a adotar uma postura mais proativa e assertiva, ponderando e estabelecendo uma política de balanceamento rígido limitado, que "depende de acúmulo limitado de armas, alianças semiformais e parcerias estratégicas" (HAN \& PAUL, 2020:5). É o exemplo da parceria estratégica com a Rússia. Tal parceria nunca chegou a formar uma aliança formal contra hegemônica. O presidente do comitê de relações exteriores do Congresso Nacional do Povo Fu Ying "afirmou que a parceria russo-russa é 'complexa, robusta e profundamente enraizada', mas 'a China tem nenhum interesse em uma aliança formal com a Rússia " (LARSON, 2020:174). De acordo com HAN \& PAUL (2020:6), 
nenhuma das duas potências querem ser alvos de retaliações de uma política de balanceamento rígido com os Estados Unidos. Além disso, a ideologia anti-EUA não é forte o suficiente na China ou na Rússia para fornecer uma base sólida para uma aliança de segurança que consiga equilibrar a balança de poder.

A menos que as ameaças dos Estados Unidos superem seus interesses divergentes, a parceria estratégica China-Rússia ainda está para se tornar uma aliança militar como as que existiam durante a Guerra Fria. A política assimétrica de aumento em gastos militares, por exemplo, é calculada como parte da política de balanceamento rígido limitado da China.

O Livro Branco de 2015, sobre a estratégia militar da China define a doutrina militar da China como uma 'estratégia ativamente defensiva'. A frase 'ativamente defensiva' implica que a China não iniciará uma guerra ofensiva contra outros estados, mas que se a China for atacada, poderá usar táticas ofensivas para eliminar a capacidade ofensiva do antagonista. (HAN e PAUL,2020:7)

Os pensadores chineses acreditam que no cenário de concorrência estratégica, a China deve variar sua política externa entre o balanceamento suave e rígido limitado, pois sua política de não alinhamento e sua política de desenvolvimento pacífico poderão neutralizar as ameaças do poder hegemônico estadunidense.

A disputa na atual conjuntura é sobre a narrativa das políticas em torno de um problema mundial, a pandemia do novo coronavírus. A narrativa americana acusa a China, na tentativa de gerar desprestígio e afastar os Estados do sistema internacional de uma parceria com a China, uma política de quem sente o seu poder hegemônico ameaçado. A narrativa chinesa é da luta e combate mundial contra o vírus. Não é um problema da China ou dos Estados Unidos, é um problema mundial. O discurso de apoio, solidariedade, são exemplos morais de liderança. Esse cenário desnuda completamente as pretensões hegemônicas dos Estados Unidos e aproxima a China de exercer a tão sonhada autoridade humana.

\section{Considerações Finais}

A inevitabilidade de uma Nova Guerra Fria é a mais pura expressão da perspectiva ocidental da ascensão chinesa ao poder mundial, assim como a própria expressão Guerra Fria, uma expressão estadunidense da disputa com a União Soviética, uma forma de engajar a sua política mundial e obter apoio da sua sociedade. Essa voz uníssona vem da reprodução de fontes ocidentais que usam as teorias que explicam as relações internacionais da sua própria perspectiva. Como se 
não houvesse uma alternativa diferente para o mundo. A quem interessa esse discurso da inevitabilidade de uma Nova Guerra Fria? A quem interessa isolar o poder chinês do sistema internacional? A quem interessa a ideia de transformar a competição estratégica numa disputa ideológica? Essa é a real necessidade de estudar como os pensadores e teóricos das relações internacionais chineses vêm desenvolvendo a sua própria perspectiva.

Está longe de ser um consenso a inevitabilidade de uma Nova Guerra Fria, pelo contrário, para os teóricos chineses é responsabilidade da China e dos EUA evitarem esse cenário de confronto direto. A perspectiva geopolítica da China propõe que da competição e do acirramento nas relações sino-americanas resulte o reconhecimento mútuo e não uma disputa existencial de vida ou morte, como foi no caso da Guerra Fria.

Nos últimos dez anos, a China vem estudando o teor das relações sinoamericanas, aplicando todo o seu repertório cultural e histórico, produzindo conceitos e métodos que podem aprimorar a análise das relações internacionais com soluções novas para problemas antigos. A contribuição da perspectiva chinesa tem a primazia de ser uma alternativa ao pensamento uníssono do ocidente, afirmando: até que todas as possibilidades estejam esgotadas, a história não acabou. O centro do mundo, como já afirmou o geógrafo brasileiro Milton Santos, está em todos os lugares. Os pensadores chineses deram um pequeno passo em busca de um mundo com múltiplas perspectivas e encontraram um universo de amplas possibilidades.

\section{REFERÊNCIAS}

ACHARYA, A. From Heaven to Earth: 'Cultural Idealism' and 'Moral Realism' as Chinese Contributions to Global International Relations. The Chinese Journal of International Politics, Volume 12, Issue 4, Winter 2019, 467-494pp. Disponível em:

< https://doi.org/10.1093/cjip/poz014>. Acesso em: 22/05/2020.

CHENGQIU, W. Ideational Differences, Perception Gaps, and the Emerging Sino-US Rivalry. The Chinese Journal of International Politics, Volume 13, Issue 1, Spring 2020, pp. 27-68. Disponível em: < https://doi.org/10.1093/cjip/poz020>. Acesso em: 22/05/2020.

CUNNINGHAN-CROSS, L. \& CALLAHAN, William A. Ancient Chinese Power, Modern Chinese Thought. The Chinese Journal of International Politics, Volume 4, Issue 4, Winter 2011, pp. 349-374. Disponível em: <https://doi.org/10.1093/cjip/por018> . Acesso em: 20/05/2020. 
FANG, H. Jianli zhongguo de guoji guanxi lilun ('Establishing the International Relation Theory with Chinese Characteristic'). Shijie jingji yu zhengzhi (World Economy and Politics), No. 1 (1992), pp. 36-9.

FLINT, C. \& XIAOTONG, Z. Historical-Geopolitical Contexts and the Transformation of Chinese Foreign Policy. The Chinese Journal of International Politics, Volume 12, Issue 3, Autumn 2019, pp. 295-331. Disponível em: <https://doi.org/10.1093/cjip/poz011>. Acesso em: 22/05/2020.

HAN, Z. \& PAUL, T. China's Rise and Balance of Power Politics. The Chinese Journal of International Politics, Volume 13, Issue 1, Spring 2020, pp. 1-26. Disponível em: <https://doi.org/10.1093/cjip/poz018>. Acesso em: 20/05/2020.

LARSON, D.W. Can China Change the International System? The Role of Moral Leadership. The Chinese Journal of International Politics, fevereiro de 2020. Disponível em: $<$ https://doi.org/10.1093/cjip/poaa002>. Acesso em: 20/05/2020.

MACKINDER, H.J. O Pivô Geográfico da História. GEOUSP: Espaço E Tempo v.15, n. 1, Dezembro de 2011, 88-100pp. Disponível em: <https://doi.org/10.11606/issn.21790892.geousp.2011.74189>. Acesso em: 22/05/2020.

PU, X. Controversial Identity of a Rising China. The Chinese Journal of International Politics, Volume 10, Issue 2, Summer 2017, 131-149pp. Disponível em: <https://doi.org/10.1093/cjip/pox004>; Acesso em: 22/05/2020.

SANTOS, M. Por uma outra globalização - Do pensamento único à consciência universal. Rio de Janeiro: Record, 2006.

TINGYANG, Z. A Neglected Project for Tianxia System. Paper presented to the international conference on 'Global IR and Non-Western IR Theory', China Foreign Affairs University, 24 April, 2018, pp. 1-2.

WEI, L. Towards Economic Decoupling? Mapping Chinese Discourse on the China-US Trade War. The Chinese Journal of International Politics, Volume 12, Issue 4, Winter 2019, 519-556pp. Disponível: <https://doi.org/10.1093/cjip/poz017>. Acesso em: 20/05/2020.

XUETONG, Y. Inertia of History: China and the World By 2023. Cambridge Scholars Publisher, 2019; pp. 240.

XUETONG, Y. Leadership and the Rise of Great Powers. The Princeton-China Series. Princeton University Press, 2019; pp. 280.

XUETONG, Y. From Keeping a Low Profile to Striving for Achievement. The Chinese Journal of International Politics, volume 7, edição 2, verão de 2014, 153-184pp. Disponível em: <https://doi.org/10.1093/cjip/pou027>. Acesso em: 22/05/2020.

XUETONG, Y. New Values for New International Norms. China International Studies, No. 38 (2013), p. 17.

XUETONG, Y. HAIXIAY, Q. Football Game Rather Than Boxing Match: China-US Intensifying Rivalry Does not Amount to Cold War. The Chinese Journal of International Politics, Volume 5, Edição 2, Verão de 2012, Páginas 105-127. Disponível em: <https://doi.org/10.1093/cjip/pos007>. Acesso em: 20/05/2020.

XUETONG, Y. Ancient Chinese Thought, Modern Chinese Power. The Princeton-China Series. Princeton University Press, 2011. 
YAQING, Q. Guoji guanxi lilun zhongguo xuepai shengcheng de keneng yu biran ('The Possibilities and Necessity of the Chinese School of International Relations Theory'). Shijie jingji yu zhengzhi (World Economy and Politics). No. 3 (2006), pp. 7-13.

ZHAO, W. Is a New Cold War Inevitable? Chinese Perspectives on US-China Strategic Competition. The Chinese Journal of International Politics , Volume 12, Edição 3, Outono de 2019, 371-394. Disponível em: <https://doi.org/10.1093/cjip/poz010>. Acesso em: $22 / 05 / 2020$.

ZICHENG,Y. Guoji guanxi yanjiu zhong de zhongguo shiye ('Os pontos de vista chineses no estudo de relações internacionais'). Waijiao pinglun ( Foreign Affairs Review ), $\mathrm{n}{ }^{\circ} 3$ (2005), pp. 64-71.

\section{NOTAS DE AUTOR}

\section{CONTRIBUIÇÃO DE AUTORIA}

Filipe Giuseppe Dal Bo Ribeiro - Concepção. Coleta de dados, Análise de dados, Elaboração do manuscrito, revisão e aprovação da versão final do trabalho

\section{FINANCIAMENTO}

Não se aplica

\section{CONSENTIMENTO DE USO DE IMAGEM}

Não se aplica

\section{APROVAÇÃO DE COMITÊ DE ÉTICA EM PESQUISA}

Não se aplica

\section{CONFLITO DE INTERESSES}

Não se aplica.

\section{LICENÇA DE USO}

Este artigo está licenciado sob a Licença Creative Commons CC-BY. Com essa licença você pode compartilhar, adaptar, criar para qualquer fim, desde que atribua a autoria da obra.

\section{HISTÓRICO}

Recebido em: 16-07-2020

Aprovado em: 21-09-2020 